QUADERNS DE FILOSOFIA VOL. III NÚM. 2 (20I6): I 29-50

ISSN: 234I-I4I 4 eISSN: 234I-3042 DOI: IO.7203/QFIA.3.I.8999

W. K. Clifford

\title{
L'ètica de la creença
}

Traducció: Alberto Oya

\section{EL DEURE D'INVESTIGAR}

$\mathrm{U}$ N NAVILIER estava a punt d'enviar a la mar un vaixell que duia un grup d'emigrants. Sabia que el vaixell era vell i que no presentava unes condicions tan bones com al principi; que havia vist molts mars i climes, i que sovint havia necessitat reparacions. Els dubtes el feren pensar que possiblement el vaixell no estava en situació de fer-se a la mar. Aquests dubtes el turmentaren i el feren infeliç; pensà que potser hauria de sotmetre'l a una completa revisió i reparació, encara que això li portés una gran despesa econòmica. No obstant això, abans que el vaixell es fes a la mar, tingué èxit a vèncer aquestes cavil.lacions malenconioses. Es digué a si mateix que el vaixell s'havia embarcat sense riscos en tants viatges i havia capejat tantes tempestes que no tenia sentit suposar que no tornaria també sa i estalvi d'aquest viatge. Posaria la seva sort en mans de la Providència, que difícilment podria fallar a protegir totes aquestes infelices famílies que deixaven la seva terra materna en la cerca de temps millors en altres indrets. Es trauria del cap totes les gasives sospites relacionades amb l'honestedat dels constructors i contractistes. D'aquesta manera, el navilier adquirí la convicció sincera i confortable que el vaixell era completament segur i estava preparat per fer-se a la mar; en veié la sortida amb el cor alegre i amb desitjos benvolents per l'èxit dels emigrants en la que seria la seva nova i desconeguda llar; i no digué res quan el vaixell s'enfonsà i cobrà els diners de l'assegurança.

Què direm d'ell? Això segur: que fou realment culpable de la mort d'aquella gent. Hem suposat que creia sincerament en la solvència del vaixell; però la sinceritat de la seva convicció no pot ajudar-lo de cap manera, perquè 
no tenia cap dret a creure a partir de l'evidència de què disposava. ${ }^{1}$ No va adquirir la creença honestament, per mitjà d'una investigació pacient, sinó fent callar els seus dubtes. I encara que al final es podria haver sentit tan segur d'aquesta creença com per no poder pensar de manera contrària, en la mesura que ell mateix s'ha mogut voluntària i conscientment cap a aquesta creença, n’ha de ser considerat responsable.

Canviem l'exemple una mica i suposem que, després de tot, el vaixell no estava en mal estat; que va fer el seu viatge amb seguretat i molts altres després d'aquest. Reduirà això la culpa del seu propietari? Gens ni mica. Una vegada es duu a terme una acció, aquesta és correcta o incorrecta per sempre; cap fracàs accidental de les seves conseqüències, bones o dolentes, pot canviar això. L'home no hauria estat innocent, tan sols no s'hauria descobert la seva culpabilitat. La pregunta sobre allò correcte i incorrecte té a veure amb l'origen de la seva creença, no amb el seu contingut; no quina era, sinó com arribà a tenir-la; no si acaba essent vertadera o falsa, sinó si ell tingué o no el dret a creure a partir de l'evidència de què disposava.

Hi havia una vegada una illa on alguns dels seus habitants professaven una religió que no ensenyava ni la doctrina del pecat original ni tampoc aquella del càstig etern. Corregué la sospita que els mestres d'aquesta religió havien fet ús de mitjans improcedents per ensenyar les seves doctrines als nens. Foren acusats de violar les lleis del seu país, atès que foren acusats d'apartar els nens de la cura dels seus guardians naturals i legals, i inclús de mantenir-los aillats i privar-los dels seus amics i de les seves relacions. Un cert nombre d'homes s'agruparen amb l'objectiu d'agitar l'opinió pública sobre aquest assumpte. Publicaren greus acusacions contra els ciutadans particulars de major posició i reputació, i feren tot el que estigué al seu abast per perjudicar a aquests ciutadans pel que fa a l'exercici de les seves professions. Tan gran fou l'enrenou que feren, que es nombrà una comissió per investigar els fets; però després que la comissió hagués examinat curosament totes les evidències que podia aconseguir, va resultar que els acusats eren innocents. No és tan sols que foren acusats a partir d'una evidència insuficient, sinó que l'evidència sobre la seva innocència era de tal mena que els agitadors l'haurien pogut obtenir facilment si haguessin intentat dur a terme una investigació justa. Després que això es féu públic, els habitants d'aquesta regió veieren als agitadors no només com a persones de les quals s'havia de desconfiar dels seus judicis, sinó també com a persones que ja no podien ser tingudes com a individus honorables. Atès que, encara que cregueren sincerament i conscientment en les acusacions que feren, tanmateix no tenien cap dret a creure a partir de l'evidència de què disposaven. Les seves sin-

\footnotetext{
${ }^{1}$ Totes les cursives són de l'autor.
} 
ceres conviccions, en comptes de ser obtingudes honestament per mitjà d'una investigació pacient, foren furtades escoltant la veu del prejudici i la passió.

Canviem també aquest cop l'exemple i suposem que la resta de coses romanen igual que abans però que una investigació encara més acurada demostra que els acusats foren realment culpables. Causaria això alguna diferència en la culpabilitat dels acusadors? Clarament no; la qüestió no és si la seva creença era vertadera o falsa, sinó si la mantingueren sobre fonaments incorrectes. No hi ha dubte que ells dirien: "Després de tot, veieu ara que teníem raó; el pròxim cop potser ens creureu”. I podrien ser creguts, però no per això esdevindrien homes honorables. No haurien estat innocents, tan sols no s'hauria descobert la seva culpabilitat. Cadascun d'ells, si escullen examinar-se a si mateixos in foro conscientiae, sabrien que han adquirit i alimentat una creença sense tenir cap dret a creure en ella a partir de l'evidència de què disposaven; i amb això sabrien que han fet quelcom incorrecte.

Podria dir-se, tanmateix, que en aquests casos que hem suposat no és la creença el que es jutja com a equivocada sinó l'acció que se segueix d'ella. El navilier podria dir: "Estic completament segur que el meu vaixell es troba en bones condicions, però encara tinc la sensació que és el meu deure examinar-lo abans de confiar-li la vida de tantes persones". I a l'agitador se li podria dir: "Per molt convençut que estiguessis de la justesa de la teva causa i de la veritat de les teves conviccions, no hauries d'haver atacat públicament la reputació de cap home fins que haguessis examinat les evidències d'una i altra banda amb el màxim de paciència i cura".

En primer lloc, admetem que aquesta visió de l'exemple és, fins allà on arriba, correcta i necessària: correcta perquè fins i tot quan la creença d'un home està tan fixada que no pot pensar d'una altra manera, encara té una opció respecte l'acció que la creença suggereix i, per tant, no pot escapar al deure d'investigar allò que fonamenta la força de les seves conviccions; i necessària, perquè aquells qui no són capaços de controlar els seus sentiments i pensaments han de tenir, tanmateix, una norma clara que s'ocupi dels seus actes públics.

Encara que això es consideri necessari, resulta clar que no és suficient, i que es requereix que el nostre judici anterior el complementi. Atès que no és possible separar la creença de l'acció que aquesta suggereix per poder condemnar-ne una sense condemnar l'altra. Ningú que mantingui una forta creença en un bàndol concret d'una qüestió, o inclús que desitgi mantenir una creença en un bàndol concret, pot investigar la qüestió amb tal justícia i plenitud com si realment es trobés en el dubte i en la imparcialitat; així doncs, l'existència d'una creença que no es basi en una justa investigació incapacita a qualsevol home de dur a terme el seu necessari deure. 
Tampoc és realment una creença aquella que no té cap influència sobre les accions d'aquell qui la manté. Aquell qui realment creu en allò que el duu a la realització d'una acció, ha mirat tant cobejosament l'acció que se'n deriva de la seva creença que ja s'ha compromès en el seu cor. Si la creença no es fa realitat immediatament en actes públics, s'emmagatzema per al guiatge del futur. Passa a formar part d'aquell agregat de creences que constitueix el nexe entre sensació i acció en cada instant de les nostres vides, el qual està tan organitzat i tan compactat entre si que cap de les seves parts pot aïllar-se de la resta, sinó que cada adició modifica l'estructura del total. Cap creença real, per molt fútil i fragmentària que pugui semblar, no és mai completament insignificant; ens prepara per rebre altres de semblants, confirma aquelles que abans se li semblaven, i en debilita d'altres; i així gradualment configura una subreptícia sèrie en els nostres pensaments més íntims, que algun dia pot derivar en un comportament públic i deixar per sempre el seu segell sobre el nostre caràcter.

I la creença d'un home no és, en cap cas, un assumpte privat que el concerneixi només a ell. Les nostres vides es guien per aquella concepció general sobre el curs de les coses que ha estat creada per la societat en vistes a fins socials. Les nostres paraules, les nostres frases, les nostres formes, processos $\mathrm{i}$ maneres de pensar són de propietat comuna, que es modelen i perfeccionen de generació en generació; una valuosa herència que tota generació venidora hereta com un preciós dipòsit i una sagrada veritat que ha de ser transmesa a la següent generació, no igual sinó engrandida i purificada, amb algunes marques clares de la seva manipulació apropiada. En això, per bé o per mal, s’entrellaça cadascuna de les creences de cadascun dels homes que han parlat amb els seus congèneres. Un privilegi terrible, i una responsabilitat terrible, que nosaltres hàgim d'ajudar a crear el món en què viurà la posteritat.

En els dos exemples hipotètics que s'han considerat s'ha jutjat erroni creure a partir d'una evidència insuficient, o alimentar una creença silenciant els dubtes i evitant la investigació. No és difícil trobar el perquè d'aquest judici: en tots dos casos la creença mantinguda per un home fou de gran importància per a altres homes. Però en tant que no hi ha mai cap creença mantinguda per un sol home que sigui realment insignificant o sense cap efecte sobre el destí de la humanitat, per molt trivial que sembli la creença i per molt enigmàtic que sembli el creient, no tenim altra opció que estendre el nostre judici a tots els casos de creença, siguin quins siguin aquests. La facultat de creure, una facultat sagrada que suscita les decisions de la nostra voluntat i teixeix totes les energies compactades del nostre ser en un mecanisme harmoniós, és nostra no per a nosaltres, sinó per a la humanitat. És usada correctament en les veritats que han estat establertes per una llarga experiència i un esforç pacient, i que s'han mantingut dempeus després de la ferotge llum del interrogatori lliure i valent. 
És llavors que ajuda a unir els homes i a enfortir i dirigir la seva acció comuna. És profanada quan s'entrega a afirmacions que mai han estat qüestionades ni provades, per al solaç i plaer privat del creient; per afegir un esplendorós oripell al senzill camí recte de la nostra vida i desplegar un brillant miratge davant d'aquest; o inclús per ofegar les penes que són comunes a la nostra espècie per mitjà d'un autoengany que li permet no només abatre'ns, sinó també degradar-nos. En aquest assumpte, mereixerà el bé dels seus congèneres aquell qui guardi la puresa de la seva creença amb una cura molt gelosa i fanàtica, per tal que no hagi mai de descansar en un objecte sense valor i agafi una taca que mai pugui ser eixugada.

No són només el líder, l'home d'estat, el filòsof o el poeta qui tenen aquest ineludible deure envers la humanitat. Qualsevol camperol que pronuncii a la taverna del poble lentes i estranyes frases pot ajudar a matar o a mantenir amb vida les fatals supersticions que frenen la seva raça. Qualsevol diligent esposa d'un artesà pot transmetre als seus fills creences que poden unir la societat, o que poden fer-la miques. Ni la simplicitat mental ni la baixa posició social poden escapar al deure universal de qüestionar tot allò que creiem.

És veritat que aquest és un deure difícil i que el dubte que en sorgeix és sovint quelcom molt amarg. Ens deixa nus i impotents allà on ens crèiem forts i segurs. Saber-ho tot sobre alguna cosa és saber com tractar-hi sota totes les circumstàncies. Ens sentim molt més feliços i segurs quan pensem que sabem de manera precisa què fer, no importa què succeeixi, que quan hem perdut el nostre camí i no sabem on dirigir-nos. I si hem suposat que ho sabem tot sobre una cosa i que som capaços de fer allò que hi és adequat, és natural que no ens agradi descobrir que en realitat som ignorants i impotents, que hem de començar un altre cop des del principi i intentar aprendre què és aquesta cosa i com tractar-hi — si és que, de fet, s'hi pot aprendre alguna cosa—. És la sensació de poder que acompanya la sensació de coneixement el que fa els homes desitjosos de creure i temorosos de dubtar.

Aquesta sensació de poder és el millor i el més elevat dels plaers quan la creença en què es basa és vertadera i ha estat obtinguda de manera justa, per mitjà de la investigació. Atès que llavors podem amb raó sentir que és de propietat comuna, i que és bona per als altres així com per a nosaltres mateixos. Llavors podem estar satisfets, no perquè jo hagi après secrets amb els quals em trobo més segur i més fort, sinó perquè nosaltres, els homes, hem obtingut el domini d'una major part del món: serem forts, però no per nosaltres mateixos, sinó en el nom de la humanitat i la seva força. Però si la creença ha estat acceptada a partir d'una evidència insuficient, es tractarà d'un plaer robat. No només ens enganyarà en aportar-nos una sensació de poder que realment no tenim, sinó que serà també pecaminós, atès que l'haurem obtinguda desobeint 
el nostre deure envers la humanitat. El nostre deure és protegir-nos d'aquesta mena de creences com si es tractés de la pesta, que en poc temps pot vèncer el nostre propi cos i després propagar-se a la resta de la ciutat. Què pensaríem d'aquell qui, en vistes a prendre una fruita dolça, corregués deliberadament el risc de portar una plaga a la seva família i els seus veïns?

I, com en altres casos similars, no només ha de tenir-se en compte el risc, atès que una acció dolenta és sempre dolenta en el moment en què es fa, sense importar què succeeixi després. Cada vegada que ens permetem creure a partir de raons insuficients, debilitem les nostres capacitats d'autocontrol, de dubtar, de sospesar les evidències justament $\mathrm{i}$ judiciosament. Tots nosaltres patim de forma prou severa a causa del manteniment i el suport de falses creences i de les accions fatalment incorrectes a què aquestes ens duen; i el mal que neix quan una creença d'aquesta mena és acceptada és gran i profund. Però un mal més gran i més profund sorgeix quan es manté i es dóna suport al caràcter crèdul, quan s'adopta i es fa permanent l'hàbit de creure a partir de raons insuficients. Si robo diners a algú, pot ser que el mer canvi de propietat no ocasioni cap dany a ningú; pot ser que aquella persona no senti la pèrdua, o pot ser que li impedeixi d'usar els diners incorrectament. No obstant això, no puc evitar aquest important greuge envers la humanitat: que em torno una persona deshonesta. El que malmet la societat no és que algú perdi una propietat, sinó que esdevingui un cau de lladres; atès que llavors deixa de ser una societat. Aquesta és la raó de perquè no hem de fer el mal perquè el bé pugui realitzar-se; perquè, en tot cas, ja ha tingut lloc aquest gran mal: que hem fet el mal i, per això mateix, ens hem fet malvats. De la mateixa manera, si em permeto creure qualsevol cosa a partir d'una evidència insuficient, potser la mera creença no causa cap dany important: pot ser verdadera després de tot, o pot ser que no tingui mai l'ocasió de manifestar-la en actes externs; no obstant això, no puc evitar aquest important greuge envers la humanitat: que em torno una persona crèdula. El perill per a la societat no és solament que aquesta cregui coses equivocades, encara que això ja és prou important, sinó que esdevingui crèdula i perdi l'hàbit d'examinar les coses i investigar sobre elles; atès que llavors s'enfonsaria de nou en el salvatgisme.

El dany que en un home ocasiona la credulitat no es limita a fomentar un caràcter crèdul en la resta d'homes, amb el consegüent suport de falses creences. L'habitual falta de cura respecte a allò que jo crec porta a l'habitual falta de cura respecte a la veritat d'allò que els altres em diuen a mi. Els homes es diuen la veritat els uns als altres quan cadascú d'ells revereix la veritat en la seva pròpia ment i en la ment dels altres; però com pot el meu amic reverir la veritat en la meva ment quan jo mateix em descuido d'ella, quan crec coses perquè les vull creure i perquè són reconfortants i plaents? Aprendrà a proclamar 
"Pau" quan no n'hi ha? ${ }^{2}$ Per aquest camí m'envoltaré d'una espessa atmosfera de falsedat i engany, i hi hauré de viure. Potser m'importi poc a mi, en el meu castell de núvols d'il-lusions dolces i mentides amables, però importa molt a la humanitat que jo hagi deixat els meus veïns a punt per ser enganyats. L'home crèdul és pare del mentider i del trampós; viu en el si d’aquesta família, i no és cap sorpresa si esdevé com ells. Tan estretament lligats entre si estan els nostres deures, que qui guardi la totalitat de la llei però, tanmateix, no la segueixi en un sol punt, serà completament culpable.

En resum: sempre, a tot arreu, i per a tothom, està malament creure quelcom a partir d'una evidència insuficient.

Si un home, mantenint una creença que li fou ensenyada en l'infantesa o de la qual fou convençut més tard, reprimeix i allunya qualsevol dubte que li sorgeixi, evita intencionadament la lectura d'aquells llibres i la companyia d'aquells homes que discuteixin o posin en dubte la seva creença, i considera impies aquelles qüestions que no poden ser formulades facilment sense pertorbar-la; la vida d'aquest home és un greu pecat contra la humanitat.

Si aquest judici sembla sever quan s'aplica a aquelles ànimes senzilles que no han conegut mai res de millor, que han estat criades des del bressol amb el pànic al dubte i a qui se'ls ha ensenyat que el seu benestar etern depèn de què creuen, llavors això ens porta a una pregunta molt seriosa: Qui féu pecar a Israel?

Prego que se'm permeti enfortir aquest judici amb una cita de Milton: ${ }^{3}$

Un home pot ser un heretge en la veritat; i si creu les coses només perquè el seu pastor així ho diu o l'assemblea així ho determina, sense conèixer altres raons, encara que la seva creença sigui vertadera, aquesta mateixa veritat que manté esdevé la seva heretgia

I amb aquest cèlebre aforisme de Coleridge: ${ }^{4}$

${ }^{2}$ Aquesta és una expressió usada a l'Antic Testament per referir-se a les pràctiques dels falsos profetes; "aquells qui, quan tenen alguna cosa entre dents, proclamen 'Pau!', però a qui no els posa res a la boca, li declaren la guerra santa" (Mi 3:5); "Curen la fractura del meu poble a la lleugera, dient: "Pau, pau!" i jon és la pau?" (Jr. 6:14).

${ }^{3}$ John Milton (1608-1674), poeta i assagista anglès. La seva vida i les seves obres estigueren en moltes ocasions estretament vinculades al convuls moment històric i polític de l'Anglaterra de l'època, que durant aquests anys visqué l'anomenada "Revolució Anglesa"; un exemple d'això és l'obra aquí citada per Clifford, Aeropagitica, escrita per Milton com a resposta a la Licensing Order de 1643.

${ }^{4}$ Samuel Taylor Coleridge (1772-1834) és un dels màxims exponents del romanticisme anglès. 
Aquell qui comença estimant el Cristianisme més que la Veritat, seguirà estimant la seva pròpia secta o Església més que el Cristianisme, i acabarà estimantse a si mateix més que a qualsevol altra cosa

Investigar l'evidència que fonamenta una doctrina no és quelcom que es faci d'un sol cop i desprès es consideri la investigació definitivament resolta. Mai no és lícit reprimir un dubte; atès que, o bé pot ser resolt honestament per mitjà de la investigació ja realitzada, o bé prova que la investigació no estava completada.

"Però", dirà algú, "sóc un home enfeinat; no tinc temps per emprendre el llarg camí d'estudi que seria necessari per a fer-me un jutge en certa mesura competent sobre algunes qüestions, o fins i tot de ser capaç d'entendre la naturalesa dels arguments". Llavors tampoc hauria de tenir temps per a creure.

\section{El PES DE L'AUTORITAT}

Llavors, hem d'esdevenir escèptics universals, i dubtar de tot i estar sempre temorosos de fer un pas endavant fins que no hàgim comprovat personalment la fermesa del camí? Ens hem de privar de l'ajuda i el guiatge de l'enorme cos de coneixement que creix diàriament al món, perquè ni nosaltres ni cap altra persona pot possiblement comprovar una centèsima part d'aquest cos de coneixement per mitjà de l'experimentació o l'observació immediata, i perquè, encara que ho comprovéssim, no quedaria completament provat? Hem de dir mentides perquè no hem tingut cap experiència personal suficientment àmplia que justifiqui la creença que està malament fer això?

No hi ha cap perill que aquestes conseqüències se segueixin de la cura escrupolosa i l'autocontrol en l'assumpte de la creença. Aquells homes que han estat més a prop de complir el seu deure en aquest assumpte han trobat que certs principis d'importància, aquells més adequats per al guiatge de la vida, han destacat amb més força i amb més claredat en proporció a la cura i honestedat amb què foren comprovats, i han adquirit d'aquesta manera una certesa pràctica. Les creences sobre el que està bé i el que està malament, que guien les nostres accions a l'hora de tractar amb els homes en societat, i les creences sobre la naturalesa física, que guien les nostres accions a l'hora de tractar amb cossos animats i inanimats, no pateixen mai la investigació; poden prendre cura de si mateixes, sense recolzar-se en "actes de fe", el clamor dels defensors a sou o la supressió de l'evidència contrària. A més, hi ha molts casos en què el nostre deure és actuar basant-nos en probabilitats, encara que l'evidència no sigui de tal mena que justifiqui la creença present; perquè és precisament per 
mitjà d'aquesta acció, i per mitjà de l'observació dels seus resultats, que es té l'evidència que pot justificar futures creences. Així que no tenim cap raó per a témer que l'hàbit d'investigar conscienciosament hagi de paralitzar les accions de la nostra vida diària.

Però, atès que no és suficient dir "Està malament creure a partir d'evidències insuficients", sense dir al mateix temps quines evidències són suficients, investigarem ara sota quines circumstàncies ens és lícit creure en el testimoni d'altri; i, desprès, investigarem de manera més general quan i perquè podem creure allò que va més enllà de la nostra pròpia experiència, o inclús més enllà de l'experiència de la humanitat.

Preguntem-nos en primer lloc, per tant, en quins casos el testimoni d'un home és insuficient per a la creença. Un home pot dir allò que no és veritat, ja sigui sabent que no és veritat o sense saber-ho. En el primer cas, està mentint, i el seu caràcter moral és el culpable; en el segon cas, és ignorant o està equivocat, i és només el seu coneixement o el seu judici el que falla. Per tal que puguem tenir el dret d'acceptar el seu testimoni com a fonament per a creure el que està dient, hem de tenir fonaments raonables per a confiar en la seva veracitat, que realment està intentant dir la veritat en la mesura que la coneix; en el seu coneixement, que ha tingut oportunitats de conèixer la veritat sobre aquest assumpte; i en el seu judici, que ha fet un ús adequat d'aquestes oportunitats a l'hora d'arribar a la conclusió que afirma.

Tant clares i òbvies són aquestes raons que qualsevol home d'intelligència ordinària que reflexioni sobre aquest assumpte no pot no arribar a elles. Tanmateix, és veritat que moltes persones no les solen tenir en compte a l'hora d'avaluar un testimoni. De les dues preguntes, igualment d'importants per avaluar la fiabilitat d'un testimoni — "és deshonest?" i "podria estar equivocat?"-, la majoria dels homes estan completament satisfets si hom els pot donar, amb cert grau de probabilitat, una resposta negativa. Es considera que l'excel-lència del caràcter moral d'un home és el fonament per a acceptar els seus enunciats sobre coses que possiblement no pot haver conegut. Un musulmà, per exemple, ens dirà que el caràcter del seu Profeta fou tan noble i majestuós que fins i tot aquells que no creuen en la seva missió haurien de reverenciar-lo. Tan admirable fou el seu ensenyament moral, tan sàviament organitzada la gran maquinària social que va crear, que els seus preceptes no només han estat acceptats per una gran part de la humanitat, sinó que de fet han estat obeïts. D'una banda, les seves institucions han rescatat el negre del salvatgisme i, d'altra banda, han ensenyat civilització a l'avançat Occident; i tot $\mathrm{i}$ que les races que han adoptat les formes més elevades de la seva fe, i han encarnat de manera més completa la seva mentalitat i els seus pensaments, han estat totes elles conquerides i esborrades del mapa per tribus bàrbares, 
tanmateix la història dels seus meravellosos assoliments roman com una glòria eterna per a l'Islam. Hem de dubtar de la paraula d'un home tan magne i bo? Podem suposar que aquest majestuós geni, aquest magnífic heroi moral, ens ha mentit sobre els assumptes més solemnes i sagrats? El testimoni de Mahoma és clar: que no hi ha sinó un únic Déu, i que ell, Mahoma, és el seu profeta; que si creiem en ell gaudirem d'una felicitat perpetua, però que si no ho fem serem condemnats. Aquest testimoni descansa en els fonaments més espaterrants, la revelació del propi Cel: atès que no fou Mahoma visitat per l'àngel Gabriel, quan dejunava i resava en la seva cova al desert, i el deixà entrar en els beneïts camps del Paradís? De ben segur que Déu és Déu i Mahoma és el profeta de Déu.

Què hem de respondre a aquest musulmà? En primer lloc, sens dubte, hauríem de tenir la temptació de rebutjar la seva opinió sobre el caràcter del Profeta i la influència uniformement beneficiosa del Islam: per poder compartir la seva opinió en aquests assumptes, semblaria que abans ens hauríem d'oblidar de moltes coses terribles que hem escoltat o llegit. Però tot i que escollim donar-li la raó en aquests supòsits per poder desenvolupar l'argument, i perquè és difícil tant per als creients com per als infidels discutir-los de manera justa i sense passió, tanmateix, encara tindríem quelcom a dir que esvairia el fonament de la seva creença i que, per tant, mostraria que està malament creure-hi. A saber: el caràcter de Mahoma és una evidència excel-lent del fet que era honest i deia la veritat en la mesura que la coneixia; però no és en cap cas evidència del fet que sabia quina era la veritat. Quins mitjans tenia per a saber que la figura que a ell li semblà l'àngel Gabriel no era una al-lucinació, i que la seva aparent visita al Paradís no fou un somni? Suposant que ell mateix estava completament convençut i creia honestament que tenia el guiatge dels Cels i que era el vehicle d'una revelació supranatural, com podia saber que aquesta ferma convicció no era un error? Posem-nos en el seu lloc: trobarem que com més intentem entendre què passava pel seu cap, més clarament percebrem que el Profeta podria no haver tingut un fonament adequat per a creure en la seva pròpia inspiració. El més probable és que ell mateix no en dubtés mai, ni pensés en qüestionar-s'ho; però nosaltres estem en el lloc d'aquells a qui se'ls hi ha fet la pregunta, i que han de respondre-la. Els metges saben que la soledat i la falta d'aliment són mitjans poderosos per a produir il.lusions i afavorir la tendència a patir un trastorn mental. Suposem, doncs, que jo, com Mahoma, vaig a llocs desèrtics a dejunar i resar; quines coses podrien passar-me que em donessin el dret a creure que estic inspirat per la divinitat? Suposem que aconsegueixo informació, aparentment d'un visitant celestial, que desprès de comprovar-la resulta ser correcta. En primer lloc, no puc estar segur que el visitant celestial no sigui un producte de la meva imaginació, i que la informació no 
hagi arribat a mi, sense saber-ho conscientment, per mitjà d'algun canal sensorial subtil. Però si aquest visitant fos un visitant real i durant una bona estona em donés informació que resultés ser fiable, això seria, de fet, un bon fonament per a confiar en ell en el futur pel que fa a aquells assumptes que cauen dins dels poders humans de verificació; però no seria un fonament per a confiar en el seu testimoni pel que fa a altres assumptes. Atès que, encara que el seu caràcter comprovat em donaria justificació per a creure que ell deia la veritat en la mesura que la coneixia, tanmateix es plantejaria la mateixa pregunta: quin fonament hi ha per a suposar que ell coneix?

Fins i tot si aquest suposat visitant m'hagués donat informació de tal mena que, desprès de jo verificar-la, provés que té mitjans de coneixement sobre assumptes verificables molt per sobre dels que jo tinc; això no em donaria justificació per a creure el que ell digués sobre assumptes que a dia d'avui no són susceptibles de ser verificats pels homes. Seria fonament per a conjectures interessants, amb l'esperança que, com a resultat de la nostra investigació pacient, poguéssim aconseguir més endavant mitjans de verificació que transformessin correctament la conjectura en creença. Atès que la creença pertany als homes i al guiatge dels assumptes humans: cap creença és real llevat que guiï les nostres accions, i aquestes accions ofereixin una prova de la seva veritat.

Tanmateix, es podria contestar que l'acceptació del Islam com a sistema és tan sols aquella acció que deriva de la creença en la missió del Profeta, i que servirà com a prova de la seva veritat. És possible creure que un sistema que ha tingut tant d'èxit es fonamenti realment en una il.lusió? No només els sants individuals han trobat pau i goig en la seva creença, i han verificat aquelles experiències espirituals que es prometen als fidels, sinó que també hi ha hagut nacions que s'han elevat del salvatgisme o barbarisme a un estat social més elevat. De ben segur que tenim la llibertat de dir que s'ha actuat conforme a la creença, i que aquesta ha estat verificada.

No obstant això, només es requereix una petita reflexió per mostrar que en cap cas el que ha estat realment verificat és el caràcter supranatural de la missió del Profeta, o la fiabilitat de la seva autoritat en assumptes que nosaltres mateixos no podem comprovar, sinó només la seva saviesa pràctica en certes coses molt mundanes. El fet que els creients hagin trobat pau i goig en la seva creença ens dóna dret a dir que aquesta doctrina és una doctrina confortable i plaent per a l'ànima; però no ens dóna dret a dir que és vertadera. I la pregunta que la nostra consciència es fa sempre que se'ns tempta a creure no és si és confortable i plaent, sinó si és veritat. Que el Profeta hagi predicat certes doctrines $i$ hagi predit que en elles es trobarà confort espiritual, només prova la seva simpatia envers la naturalesa humana i el seu coneixement d'aquesta, però no prova el seu coneixement sobrehumà de la teologia. 
I si admetem, per poder desenvolupar l'argument (atès que sembla que no podem admetre-ho per cap altra raó), que realment en alguns casos el progrés de les nacions musulmanes fou a causa del sistema que Mahoma ideà $\mathrm{i}$ posà al món, no tenim la llibertat per a concloure a partir d'aquí que Mahoma estigués inspirat per declarar la veritat de coses que nosaltres no podem verificar. Només tenim la llibertat d'inferir l'excelllència dels seus preceptes morals, o dels mitjans que va idear per fer que els homes l'obeïssin, o de la maquinària política i social que va establir. I determinar quines d'aquestes coses tingueren una participació important en aquest resultat és quelcom que requeriria d'una gran quantitat d'investigació curosa sobre la història d'aquestes nacions. Així, un cop més, és el coneixement del Profeta sobre la naturalesa humana, i la seva simpatia envers la mateixa, el que està verificat; però no la seva inspiració divina, o el seu coneixement de la teologia.

De fet, si hi hagués només un Profeta, podria semblar una tasca difícil, i fins i tot grollera, decidir en quins punts hem de confiar en ell, i en quins hem de desconfiar de la seva autoritat; tenint en compte l'ajuda i el desenvolupament que tots els homes de totes les èpoques han rebut d'aquells que veieren més clarament, que sentiren més fortament, i que buscaren la veritat amb un cor més singular que el dels seus prö̈smes més dèbils. Però no hi ha només un Profeta; i mentre que el consentiment de molts sobre allò que, com a homes, tingueren mitjans reals de conèixer i conegueren, ha durat fins al final, i de manera honorable ha passat a formar part del gran sistema del coneixement humà, els diversos testimonis d'alguns sobre allò que no conegueren, i no podien conèixer, roman com un avís per a nosaltres: exagerar l'autoritat profètica és fer-ne un mal ús, i és deshonrar aquells que l'han buscada només per ajudar-nos i afavorir-nos amb el seu poder. Difícilment es troba en la naturalesa humana que un home hagi de calibrar prou adequadament els límits de la seva visió; però és el deure d'aquells que es beneficien del seu treball considerar amb deteniment on pot haver-se sobrepassat. Si haguéssim de considerar conjuntament els seus possibles errors amb els seus sòlids assoliments, i usar la seva autoritat com una excusa per creure allò que no podem conèixer, estaríem fent de la seva bondat una ocasió per al pecat.

Considerem només un altre dels testimonis d'aquesta mena: els seguidors de Buda tenen, almenys, el mateix dret a recórrer a l'experiència individual i social en suport de l'autoritat del salvador oriental. Es diu que el tret distintiu de la seva religió, respecte al qual no ha estat mai superada, és el confort i consolació que dóna al malalt i apesarat, la tendra simpatia amb què calma i apaivaga totes les penes humanes. I de ben segur que cap triomf de la moralitat social pot ser més gran o més noble que aquell que ha allunyat prop de la meitat de la raça humana a cometre persecucions en nom de la religió. 
Si hem de confiar en les explicacions dels seus primers seguidors, ell mateix va creure que havia vingut a la Terra amb una missió divina i còsmica per fer rodar la roda de la llei. Essent un príncep, es desposseí del seu regne, i per la seva pròpia voluntat es familiaritzà amb la misèria, $i$ així poder aprendre a controlar-la i dominar-la. Podria un home d'aquesta mena parlar falsament sobre coses solemnes? I, pel que fa a la seva saviesa, no fou un home miraculós amb més poders que els dels homes? Nasqué de la dona sense l'ajuda de l'home; s'elevà fins a l'aire i es transfigurà davant dels seus familiars; i finalment pujà físicament als cels des del pic d'Adam. ${ }^{5}$ No s'ha de creure en la seva paraula quan testifica de coses celestials?

Si només hi estigués ell, i cap altre, amb afirmacions d'aquesta mena! Però està Mahoma amb el seu testimoni; no podem escollir, sinó escoltar a ambdós. El Profeta ens diu que hi ha un Déu, i que viurem eternament en la joia o en la misèria, depenent de si creiem en el Profeta o no. Buda diu que no hi ha cap Déu, i que si som suficientment bons serem anihilats més endavant. Tots dos no poden estar infal.liblement inspirats; un o l'altre ha hagut de ser víctima d'una il-lusió, i ha pensat que coneixia allò que realment no coneixia. Qui s'atreveix a dir quin dels dos? I com podem estar justificats per creure que l'altre no era també víctima d'una il.lusió?

Tot això ens porta als següents judicis. La bondat i grandesa d'un home no ens dóna justificació per a acceptar una creença en virtut de la garantía de la seva autoritat, llevat que hi hagin fonaments raonables per a suposar que coneix la veritat del que està dient. I no pot haver cap fonament per a suposar que un home coneix allò que nosaltres, sense deixar de ser homes, se suposa que no podem verificar.

Si un químic em diu a mi, que no sóc químic, que es pot obtenir certa substància a partir de mesclar altres substàncies en certes proporcions i sotmetre-les a un procés conegut, estic prou justificat a creure-ho en funció de la seva autoritat, llevat que sàpiga alguna cosa en contra del seu caràcter o el seu judici. Atès que la seva formació professional tendeix a afavorir la veracitat i la cerca honesta de la veritat, i a produir aversió envers les conclusions precipitades i la investigació descurada. I tinc fonaments raonables per a suposar que coneix la veritat del que està dient, atès que tot i que no sóc químic, puc arribar a entendre prou els mètodes i processos de la ciència perquè em sigui concebible que, sense deixar de ser home, pugui verificar l'enunciat. Pot ser que no el verifiqui

${ }^{5}$ El Pic d'Adam és una muntanya situada a Sri Lanka. En el seu cim es troba una roca amb forma de petjada humana d'uns dos metres de longitud que ha fet que la muntanya sigui un lloc de peregrinatge per a budistes, hindús i musulmans. Els budistes afirmen que és la petjada de Buda, mentre que els hindús creuen que es tracta de la petjada del déu Shiva. Els musulmans, per la seva part, atribueixen el seu origen a Adam. 
mai, o inclús que no arribi a veure cap experiment que pretengui verificar-lo; però encara tinc raons suficients per a estar justificat a creure que la verificació és troba dins dels límits de les aplicacions i facultats humanes, i, en particular, que ha estat realment executada pel meu informant. El seu resultat, la creença a què l'han conduït les seves investigacions, no és només vàlid per a ell sinó també per als altres; és observada i comprovada per aquells que treballen en el mateix àmbit, i que saben que no hi ha millor servei que se li pugui fer a la ciència que purificar els resultats acceptats dels errors que puguin haver aparegut. És d'aquesta manera que el resultat esdevé de propietat comuna, un just objecte de creença, que és un afer social i un assumpte d'interès públic. Així, s'ha d'observar que la seva autoritat és vàlida perquè hi ha aquells que la qüestionen i la verifiquen; que és precisament aquest procés d'examinar i purificar el que manté viu entre els investigadors l'amor a allò que superarà totes les proves possibles, el sentiment de responsabilitat pública d'aquells la feina dels quals, si està ben feta, romandrà com el perdurable llegat de la humanitat.

Però si aquest químic em diu que un àtom d'oxigen ha existit sempre sense patir cap alteració pel que fa al seu pes i intensitat de vibració, no tinc cap dret a creure-ho en funció de la seva autoritat, atès que és quelcom que ell no pot arribar a conèixer sense deixar de ser home. Potser creu honestament que el seu enunciat és una inferència correcta dels seus experiments, però en aquest cas el seu judici falla. Una reflexió molt senzilla sobre el caràcter dels experiments li faria veure que aquests mai poden dur a resultats d'aquesta mena; essent només aproximats i limitats, no poden donar-nos un coneixement exacte i universal. Cap genialitat o eminència de caràcter pot donar a un home autoritat suficient per a justificar-nos a creure'l quan fa enunciats que impliquen coneixement exacte o universal.

D'altra banda, un explorador de l'Àrtic podria dir-nos que en unes latituds i longituds determinades ha experimentat tal i tal grau de fred, que el mar era de tal profunditat, i el gel de tal mena. Tenim tot el dret a creure'l, en absència de cap taca en la seva veracitat. És concebible que, sense deixar de ser homes, poguéssim anar allà i verificar el seu enunciat; pot ser comprovat pel testimoni dels seus companys, i hi ha fonaments adequats per a suposar que coneix la veritat del que està dient. Però si un vell balener ens digués que el gel té un gruix de tres-cents peus en tot el camí fins al Pol, ${ }^{6}$ no estaríem justificats a creure'l. Atès que, encara que el seu enunciat pot ser verificat pels homes, certament no pot haver estat verificat per $e l l$, amb els mitjans i instruments que posseïa; i s'haurà d'haver convençut de la veritat del seu enunciat a través de mitjans que no aporten cap credibilitat al seu testimoni. Per tant, inclús si

${ }^{6} 300$ peus equivalen a 91,44 metres. 
l'assumpte afirmat es troba dins dels límits del coneixement humà, no tenim cap dret a acceptar-lo a partir d'una autoritat llevat que aquest es trobi dins dels límits del coneixement del nostre informant.

Què direm d'aquella autoritat, més venerable i augusta que la de qualsevol testimoni individual, la de l'ancestral tradició de la raça humana? Les tasques i lluites dels nostres ancestres han format una atmosfera de creences i conceptes que ens permet respirar enmig de les complexes i variades circumstàncies de la nostra vida. És al voltant nostre, sobre nosaltres i dins nostre; no podem pensar llevat en les formes i processos de pensament que ens proporciona. És possible dubtar i comprovar-la? I, si és possible, és correcte?

Podem trobar raons per a respondre que no és només possible i correcte, sinó que és el nostre ineludible deure, que el principal propòsit de la pròpia tradició és proporcionar-nos els mitjans per a fer-nos preguntes, de comprovar i investigar les coses; que si en fem un mal ús, i la prenem com una col-lecció d'enunciats preestablerts que han de ser acceptats sense cap investigació posterior, no només ens estem fem mal a nosaltres sinó que estem refusant de complir la nostra part envers la construcció del sistema que els nostres fills han d'heretar: ens estem separant, a nosaltres mateixos i a la nostra raça, del llinatge humà.

En primer lloc, prenguem cura de distingir un tipus de tradició que requereix especialment ser examinada i ser posada en dubte, perquè defuig especialment la investigació. Suposem que un xaman d'África Central diu a la seva tribu que certa poderosa medicina que té en la seva tenda els serà favorable si maten el seu bestiar; i que la tribu el creu. Que la medicina els hi sigui favorable o no, no hi ha mitjans per a verificar-ho, però el bestiar ja és mort. Tanmateix, la tribu pot conservar la creença que la medicina els fou favorable gràcies a aquests mitjans; i en una generació venidora serà més facil per a algun altre xaman convèncer-los que facin un acte similar. Aquí, l'única raó per a creure és que tothom ho ha cregut durant tant de temps que ha de ser veritat. I, tanmateix, la creença fou fundada en el frau, i es va propagar gràcies a la credulitat. Sens dubte farà be, i serà amic dels homes, aquell que la posi en qüestió i descobreixi que no hi ha cap evidència que la sustenta, que ajudi als seus veïns a veure el que ell veu, i inclús, si fos necessari, que entri a la tenda sagrada i trenqui la medicina.

La norma que ens ha de guiar en aquests casos és prou òbvia i senzilla: que la suma del testimoni dels nostres veïns està subjecte a les mateixes condicions que el testimoni de qualsevol d'ells. És a dir: no tenim cap dret a creure que una cosa és veritat perquè tothom digui que ho és, llevat que hi hagi bons fonaments per a creure que almenys alguna persona té els mitjans per a conèixer què és vertader, i que està dient la veritat en la mesura que la coneix. 
Malgrat que moltes nacions i generacions d'homes s'han dut a l'estrada, no poden testificar res que no coneguin. Tot aquell que hagi acceptat un enunciat d'altri, sense haver-lo comprovat i verificat ell mateix, està fora de la llei; la seva paraula no té cap mena de valor. I, al capdavall, quan tornem al veritable naixement i origen de l'enunciat, se'ns plantegen dues preguntes serioses sobre qui primer féu l'enunciat: estava equivocat a pensar que sabia respecte d'aquest assumpte, o estava mentint?

Aquesta pregunta és, desafortunadament, molt actual i pràctica, inclús per a nosaltres, avui dia i en aquest país. No hem d'anar a La Salette, o a l'África Central, o a Lourdes ${ }^{7}$ per trobar exemples de supersticions immorals i envilidores. És molt possible que un nen creixi a Londres envoltat d'una atmosfera de creences que, essent només pròpies del salvatge, en la nostra pròpia època es fonamenten en el frau i es propaguen per la credulitat.

Deixant de banda, doncs, aquesta mena de tradició que és transmesa de generació en generació sense ser comprovada, considerem ara aquella tradició que realment s'ha constituït a partir de l'experiència comuna de la humanitat. Aquest gran sistema és per al guiatge dels nostres pensaments i, a través d'ells, de les nostres accions, tant en el món moral com en el món material. En el món moral, per exemple, ens dóna els conceptes del que està bé en general, de justícia, de veritat, de beneficència i d'altres semblants. Se'ns presenten com a conceptes, no com a enunciats o proposicions; responen a certs instints definits, que estan certament dins nostre, sigui com sigui que hi han arribat. Que està bé ser benèfic és assumpte de l'experiència personal immediata; atès que quan un home es retira a dins de si mateix i troba alguna cosa més àmplia i més duradora que la seva solitària personalitat, que diu "vull fer el que està bé", així com "vull fer bé a l'home", pot verificar per mitja de l'observació directa que un dels instints està fundat sobre l'altre, i està totalment d'acord amb ell. I és el seu deure verificar aquesta i altres afirmacions similars.

La tradició diu també que, en un lloc i en un temps determinats, aquestes o aquelles accions són justes, o vertaderes, o benèfiques. Totes aquestes normes necessiten de més investigació, atès que a vegades s'estableixen a partir d'una autoritat diferent al sentit moral fonamentat en l'experiència. Fins fa poc, la tradició moral del nostre propi país — i, de fet, de tot Europa- ensenyava que donar diners als captaires indiscriminadament era un acte benèfic. Però el qüestionament d'aquesta norma, i la investigació sobre ella, dugueren els homes a veure que la veritable beneficència és aquella que ajuda a l'home a fer la

${ }^{7}$ Segons l'Església catòlica, la Verge Maria s'aparegué a La Salette (1846) i a Lourdes (1858). Com a conseqüència, des de mitjans del segle XIX, aquests dos pobles francesos són importants centres de peregrinatge catòlic. 
feina que millor se li adequa, i no pas aquella que l'anima i manté en l'ociositat; i que obviar aquesta distinció avui és preparar pauperisme i misèria per demà. Mitjançant aquest provar i discutir, no només la pràctica s'ha purificat i s'ha fet més benèfica, sinó que el propi concepte de beneficència s'ha fet més ampli i més savi. Ara bé, aquí el gran llegat social consisteix de dues parts: l'instint de beneficència, que, quan predomina, fa que una part de la nostra natura desitgi fer el bé als homes; i el concepte intel-lectual de beneficència, que podem aplicar a qualsevol curs de conducta i preguntar-nos "és benèfic o no?". Gràcies a aquest continuat preguntar i respondre aquesta mena de qüestions, el concepte creix en amplitud i claredat, i l'instint esdevé més fort i més pur. Sembla, per tant, que el principal ús del concepte, la part intel-lectual del llegat, és fer-nos capaços de fer preguntes; que creix i es manté pel bon camí per mitjà d'aquestes preguntes; i que, si no el fem servir per a aquest propòsit, l'anirem perdent de manera gradual fins a perdre'l completament, i ens quedarem amb un mer codi de regulacions que en cap cas pot anomenar-se moralitat.

Aquestes consideracions s'apliquen fins i tot de manera més clara i més òbvia, si és possible, al conjunt de creences i conceptes sobre el món material que els nostres avantpassats han desat per a nosaltres. Estem disposats a riure'ns del costum que segueix l'australià, qui continua lligant la fulla de la destral a un dels costats del mànec, tot i que l'artesà de Birmingham hi ha fet expressament un forat per posar-hi el mànec. La seva gent ha lligat les fulles de destral durant molt de temps: qui és ell per contrariar la seva saviesa? Ha caigut tant baix que no pot fer el que algun d'ells hauria d'haver fet fa molt de temps: posar en dubte un costum establert i inventar o aprendre'n un de millor. Tanmateix, aquí, en el tèrbol començament del coneixement, on ciència i art són un, trobem tan sols la mateixa norma senzilla que s'aplica a les parts més profundes i elevades d'aquest Arbre còsmic, ${ }^{8}$ a les seves flors més elevades, així com a les més profundes de les seves arrels ocultes; a saber: la norma que allò que s'emmagatzema i se'ns transmet és usat correctament per aquells que actuen tal i com els seus creadors varen actuar quan ho varen emmagatzemar; aquells que l'usen per fer més preguntes, per examinar, per investigar; que intenten honestament i solemnement trobar quina és la manera correcta d'observar les coses i tractar amb elles.

Una pregunta ben formulada és una pregunta ja mig resposta, digué Jacobi; ${ }^{9}$ podem afegir que el mètode per a solucionar-la és l'altra meitat de la resposta, i que el resultat no compta gens al costat d'aquests dos. Com a

${ }^{8}$ Aquest "Arbre còsmic" és una clara referència a l'Arbre del Coneixement del Gènesi bíblic.

${ }^{9}$ Clifford sembla estar fent referència al matemàtic alemany Karl Gustav Jacob Jacobi (18041851), a qui se li atribueix l'expressió "man muss immer umkehren" ("sempre se li ha de donar la volta"); és a dir, que es pot trobar la solució a molts problemes si aquests són formulats de manera inversa a com solen ser plantejats. 
exemple considerem el telègraf, on teoria i pràctica, que cresqueren durant anys de discreció, estan meravellosament entrellaçades per al fructífer servei de l'home. $\mathrm{Ohm}^{10}$ trobà que la potència d'una corrent elèctrica és directament proporcional a la potència de la bateria que la produeix, i inversament proporcional a la longitud del cable que ha de transitar. Això s'anomena la llei d'Ohm; però el resultat, considerat com un enunciat que s'ha de creure, no és la part valuosa de la llei. La primera meitat és la pregunta: quina relació existeix realment entre aquestes quantitats? Dit així, la pregunta pressuposa els conceptes de potència d'una corrent i potència d'una bateria com a quantitats que s'han de mesurar i comparar; indica clarament que aquestes són les coses a les quals s'ha de parar atenció en l'estudi de les corrents elèctriques. La segona meitat és el mètode d'investigació: com es mesuren aquestes quantitats, quins instruments són necessaris per a l'experiment, i com s'han d'usar? A l'estudiant que comença a aprendre sobre electricitat, no se li demana que cregui en la llei d'Ohm: se li fa entendre la pregunta, se'l posa davant l'aparell i se li ensenya a verificar-la. Aprèn a fer coses, no a pensar que sap coses; a usar instruments i a fer preguntes, no a acceptar una afirmació tradicional. La pregunta que va necessitar d'un geni per ser preguntada correctament, és resposta pel principiant. Si de sobte tots els homes oblidessin la llei d'Ohm, mentre la pregunta i el mètode per a solucionar-la es conservessin, el resultat es podria redescobrir en una hora. Però el resultat per si mateix, si és conegut per gent que no poden comprendre el valor de la pregunta o els mitjans per a resoldre-la, és com un rellotge en les mans d'un salvatge que no pot donar-li corda, o un vaixell de vapor conduit per enginyers espanyols. ${ }^{11}$

Per tant, pel que fa a la tradició sagrada de la humanitat, aprenem que aquesta consisteix, no en proposicions o enunciats que han de ser acceptats $\mathrm{i}$ creguts en funció de l'autoritat de la tradició, sinó en preguntes correctament formulades, en conceptes que ens permeten formular més preguntes, i en mètodes de respondre aquestes preguntes. El valor de totes aquestes coses depèn de ser comprovades dia a dia. La pròpia santedat d'aquest preciós dipòsit ens imposa el deure i la responsabilitat de verificar-lo, de purificar-lo i engrandir-lo $\mathrm{amb}$ totes les nostres forces. Qui fa ús dels seus resultats per silenciar els seus

${ }^{10}$ Georg Simon Ohm (1787-1854) fou un físic alemany conegut principalment per la seva contribució a la teoria de l'electricitat. La unitat de resistència elèctrica, l'ohm $(\Omega)$, rep el seu nom en el seu honor.

${ }^{11}$ En l'edició utilitzada per a aquesta traducció es recull una carta que Clifford envià, el 2 de juliol de 1876, a Lady Pollock. La carta deia així: "Demà anem a Almeria en un vaixell espanyol, i des d'allà, en diligència o en un altre vaixell, a Màlaga. El vaixell espanyol serà horrible, però seran només unes dotze hores més o menys. [...] PS. [...] Hem vist el vaixell espanyol, que s’anomena La Encarnación, i, certament, és l'encarnació de totes les coses dolentes." Aquesta carta es troba en W. K. Clifford, Lectures and Essays, vol I. MacMillan and Co., Londres, i 879: 54-8. 
propis dubtes, o per entorpir la investigació d'altres, és culpable d'un sacrilegi que els segles no podran esborrar mai. Quan els treballs i els qüestionaments dels homes honestos i valents hagin construït un sistema de veritats conegudes que tingui una glòria que nosaltres en aquesta generació no podem ni imaginar, en aquest pur i sagrat temple aquell no tindrà cap mena de cabuda, sinó que el seu nom i les seves obres seran expulsades a l'obscur oblit per sempre.

\section{ELS LÍMITS DE LA INFERÈNCIA}

La pregunta d'en quins casos podem creure allò que va més enllà de la nostra experiència és molt complexa i delicada, s'estén a tot el mètode científic, i requereix d'un considerable increment en la seva aplicació abans que pugui ser contestada amb una resposta que s'acosti a la completesa. Tanmateix, aquí podem mencionar i establir breument una norma d'extremada simplicitat i d'una gran importància pràctica que es troba en el llindar d'aquest assumpte.

Una mica de reflexió ens mostrarà que tota creença, inclús les més simples i fonamentals, van més enllà de l'experiència quan se les considera com a guies per a les nostres accions. Un nen que s'ha cremat tem el foc, perquè creu que el foc el cremarà avui com el va cremar ahir; però aquesta creença va més enllà de l'experiència, i assumeix que el foc desconegut d'avui és semblant al foc conegut d'ahir. Inclús la creença que el nen es va cremar ahir va més enllà de l'experiència present, la qual conté només el record d'una cremada, però no la cremada mateixa; s'assumeix, per tant, que aquest record és fiable, encara que sabem que la memòria sovint pot equivocar-se. Però si s'ha d'usar com a guia per a l'acció, com a pista de com serà el futur, s'ha d'assumir quelcom sobre el futur; a saber: que serà compatible amb la suposició que la cremada realment tingué lloc ahir, suposició que va més enllà de l'experiència. Fins i tot el fonamental 'Jo sóc', del qual no es pot dubtar, no és una guia per a l'acció excepte que comporti 'Jo seré', que va més enllà de l'experiència. La pregunta no és, per tant, "podem creure allò que va més enllà de l'experiència?", atès que això es troba en la pròpia naturalesa de la creença; sinó "fins a quin punt i de quina manera podem anar més enllà de la nostra experiència a l'hora de formar les nostres creences?"

L'exemple que hem considerat ens suggereix una resposta, d'absoluta simplicitat i universalitat: el nen que s'ha cremat tem el foc. Podem anar més enllà de l'experiència tot assumint que el que ara no sabem és semblant al que sabem; $\mathrm{o}$, en altres paraules, podem anar més enllà de la nostra experiència sota el supòsit de la uniformitat en la natura. Què és amb precisió aquesta uniformitat? Com augmenta el nostre coneixement d'aquesta uniformitat de 
generació en generació? Aquestes són preguntes que ara per ara deixo de banda; estic satisfet amb examinar dos exemples que poden servir per fer més clara la naturalesa de la norma.

A partir de certes observacions fetes amb l'espectroscopi, ${ }^{12}$ inferim l'existència d'hidrogen en el sol. Si mirem per l'espectroscopi quan els rajos solars incideixen sobre les escletxes del sol, veiem certes línies brillants i definides: $\mathrm{i}$ els experiments que s'han fet sobre els cossos de la Terra ens ensenyen que quan es veuen aquestes línies brillants, l'hidrogen n'és l'origen. Assumim, doncs, que les desconegudes línies brillants del sol són com les conegudes línies brillants del laboratori, i que l'hidrogen del sol es comporta com l'hidrogen es comportaria a la Terra sota circumstàncies similars.

Però no estem confiant massa en el nostre espectroscopi? Atès que hem trobat que és fiable pel que fa a les substàncies terrestres, on les seves afirmacions poden ser verificades pels homes, segurament estem justificats a acceptar el seu testimoni en d'altres casos semblants; però succeeix el mateix quan ens dóna informació sobre coses que hi ha en el sol, on el seu testimoni no pot ser directament verificat per l'home?

Certament, volem saber una mica més abans que aquesta inferència pugui estar justificada; i, afortunadament, ho sabem. L'espectroscopi testifica exactament la mateixa cosa en ambdós casos; a saber: que vibracions de llum de certa intensitat s'envien a través d'ell. Està construït de tal manera que si s'equivoqués en un cas, llavors també s'equivocaria en l'altre. Quan considerem la matèria, trobem que realment hem suposat que la matèria del sol es semblant a la matèria de la Terra; que està constituïda per un cert nombre de substàncies diferents, i que cadascuna d'aquestes, quan tenen una temperatura molt elevada, presenten una intensitat de vibració diferent, mitjançant la qual es poden reconèixer i singularitzar de la resta. Però aquesta és la mena d'assumpció que estem justificats a usar quan anem més enllà de la nostra experiència. És una assumpció sobre la uniformitat en la natura, i només es pot comprovar comparant-la amb d'altres assumpcions similars que hem de fer en altres casos d'aquesta mena.

Però és això una creença verdadera sobre la existència d'hidrogen en el Sol? Pot ajudar a guiar correctament l'acció humana?

Certament no, si s'accepta sobre bases insuficients i sense cap mena de comprensió del procés pel qual s'hi arriba. Però quan es considera aquest procés com el fonament de la creença, esdevé un assumpte molt seriós i pràctic. Atès que, si no hi ha hidrogen en el sol, l'espectroscopi —és a dir, el mesurament de les intensitats de vibració- ha de ser una guia incerta a l'hora de reconèixer

${ }^{12}$ L'espectroscopi és un aparell per a produir i analitzar espectres d'una radiació electromagnètica. Fou inventat l'any 1814 per l'alemany Joseph von Fraunhofer (1787-1826). 
les diferents substàncies; i, en conseqüència, per tal d'estalviar temps, problemes i diners, no ha de ser utilitzat en l'anàlisi químic — per determinar els elements d'un objecte, per exemple-. Però l'acceptació de l'espectroscòpia com a mètode fiable no només ens ha enriquit amb nous metalls, cosa que és molt important, sinó també amb nous processos d'investigació, que és encara més important.

Un altre exemple. Considerem la manera com inferim la veritat d'un esdeveniment històric — per exemple, el setge de Siracusa en la Guerra del Peloponès-. La nostra experiència és que existeixen manuscrits dels quals es diu que són, i que ells mateixos diuen ser, manuscrits de la Història de Tucídides; ${ }^{13}$ que en altres manuscrits, els quals es creu que foren escrits per historiadors posteriors, es diu que aquest visqué durant el temps de la guerra; i que hi ha llibres, que se suposa que daten del renaixement de l'ensenyament, ${ }^{14}$ que ens diuen com s'han preservat aquests manuscrits i on foren trobats. Trobem també que, com a norma, els homes no falsifiquen llibres i històries sense tenir cap motiu especial; assumim que en això els homes del passat foren semblants als homes del present; i observem que en aquest cas no hi havia cap motiu especial. És a dir: anem més enllà de la nostra experiència sota l'assumpció de la uniformitat en els caràcters dels homes. Atès que el nostre coneixement d'aquesta uniformitat és molt menys complert i exacte que el nostre coneixement d'aquella uniformitat que s'obté en la física, les inferències històriques són més precàries i menys exactes que les inferències de moltes altres ciències.

Però si hi ha alguna raó especial per a sospitar del caràcter d'aquelles persones que escrigueren o transmeteren certs llibres, la cosa canvia. Si un grup de documents presenta la evidència interna que foren produïts entre gent que falsificava llibres en nom d'altri, i que, en descriure els esdeveniments, suprimien aquelles coses que no els hi convenien, alhora que amplificaven aquelles que sí que els convenien - i no només cometeren aquests crims sinó que es delectaren d'ells com a proves d'humilitat i zel—, llavors hem de dir que a partir d'aquests documents no es pot elaborar cap inferència històrica veritable, sinó tan sols conjectures insatisfactòries.

Podem, per tant, anar més enllà de la nostra experiència sota el supòsit de la uniformitat de la natura; podem omplir la nostra imatge del què és i del què ha sigut, tal i com l'experiència ens la dóna, de tal manera que tot sigui consistent amb aquesta uniformitat. I, en la pràctica, la inferència demostrativa

${ }^{13}$ Tucídides, historiador i militar atenenc, és conegut principalment per la seva Història de la Guerra del Peloponès. Se'l sol considerar el primer historiador, atès que en la seva obra tot gira al voltant dels homes i les seves accions, deixant de banda la presència dels déus i les descripcions mítiques.

${ }^{14}$ En l'original: "the revival of learning". Amb aquesta expressió, Clifford està fent referència al Renaixement. 
—aquella que ens dóna el dret a creure en el seu resultat- mostra clarament que no hi ha cap altra manera de salvar la uniformitat de la natura si no és per la veritat del seu resultat.

Cap evidència, per tant, ens pot donar justificació per a creure la veritat d'un enunciat que sigui contrari o que estigui fora de la uniformitat de la natura. Si la nostra experiència és de tal mena que no es pot omplir de manera consistent amb la uniformitat, tot el que tenim dret a concloure és que hi ha quelcom equivocat en algun lloc; però la possibilitat de la inferència s'ha esvaït; hem de basar-nos en la nostra experiència i en cap cas anar més enllà. Si realment succeís un esdeveniment que no fos part de la uniformitat de la natura, aquest tindria dues propietats: cap evidència podria donar el dret a creure aquest esdeveniment a ningú, excepte a aquells que realment l'haguessin experimentat; i cap inferència que fos mereixedora de ser creguda podria fonamentar-se en ella.

Estem, per tant, obligats a creure que la natura és absoluta i universalment uniforme? Certament no; no tenim cap dret a creure cap cosa d'aquesta mena. La norma només ens diu que, en formar creences que van més enllà de la nostra experiència, podem acceptar el supòsit que la natura és pràcticament uniforme fins allà on ens concerneix. Dins de l'àmbit de l'acció i la verificació humanes, podem formar-nos, amb l'ajuda d'aquest supòsit, creences vertaderes; més enllà d'això, només resten aquelles hipòtesis que serveixen per fer preguntes de manera més acurada.

En resum:

Podem creure allò que va més enllà de la nostra experiència, només quan s'infereix d'aquesta experiència a partir del supòsit que el que no sabem és semblant al que sabem.

Podem creure les afirmacions d'una altra persona, quan hi ha fonaments raonables per a suposar que sap del tema de què està parlant, i que està dient la veritat en la mesura que la coneix.

En tots els casos està malament creure a partir d'evidències insuficients; $\mathrm{i}$ on hi ha la presumpció de dubtar i investigar, és pitjor creure que la presumpció. 